\title{
DE CUANDO UN FLAUTISTA DULCE SE ENCONTRÓ CON UN LIBRO DE POESÍA NEOBARROCA Y OTRAS MUCHAS COSAS DIGNAS DE SABERSE ${ }^{1}$
}

\author{
Felipe Cussen \\ Instituto de Estudios Avanzados-Universidad de Santiago de Chile \\ felipecussen@gmail.com
}

Este es un ensayo autobiográfico. Gira en torno a un período de tiempo específico: algunos días de un verano, quizás del 2000 o el 2001, en que leí por primera vez la muestra de poesía latinoamericana Medusario. Hasta ese momento me habían ocurrido algunos asuntos indirectamente relacionados: llevaba un buen tiempo estudiando flauta dulce, y me había enfocado en el repertorio de la música europea de los siglos XVI, XVII y XVIII. Dedicaba, además, muchas horas a escuchar música de esos períodos. Aunque paralelamente también había estudiado literatura, no conocía casi nada de la poesía de esa época. Aprendí un poco más leyendo los folletos de los discos, donde aparecían los textos de ese mismo período o anteriores que habían sido adaptados por los compositores. Luego de leer Medusario descubrí a una gran cantidad de autores que me interesaron muchísimo, e incluso he tenido la suerte de conversar con algunos de ellos. Solo después sentí el impulso de acercarme con mayor atención a los poetas del Siglo de Oro español, así como a algunos contemporáneos italianos, franceses o ingleses. Un buen día, casi sin darme cuenta, terminé sentado en una reunión con gente muy importante para formar parte de un Grupo de Estudios sobre el Barroco y Neobarroco. Mientras todos desarrollaban

$1 \quad$ Este ensayo fue leído el 24 de octubre de 2013 en el 1er encuentro sobre el Barroco en Chile: Barrocos Fronterizos, en la Universidad de Chile. Corresponde a mi participación en el Grupo de Estudios sobre Barroco y Neobarroco en Chile, proyecto financiado por la Iniciativa Bicentenario de revitalización de las Humanidades, las Artes, las Ciencias Sociales y Ciencias de la Comunicación de la Universidad de Chile, y dirigido por la profesora Luz Ángela Martínez. 
definiciones muy complejas, me di cuenta de que yo nunca había pensado muy bien qué era o podría ser el barroco. Creo que dije, apenas: a mí lo que me interesa es el hipérbaton.

Mi propio recorrido por el barroco y el neobarroco ha sido como un hipérbaton. Cuando tomé por primera vez Medusario no conocía bien la mayor parte de sus referentes literarios, filosóficos y culturales, del pasado y del presente. Lo que sí tenía en mi cabeza eran muchas reglas de cómo debían sonar, articularse, ornamentarse y, especialmente, qué efectos debían provocar aquellas melodías de distintas tradiciones que, siglos después, se metieron en un gran saco llamado "música barroca". Ésas eran las nociones que tenía. Fue allí donde se montó el "nuevo" barroco de estos poetas como una variación. Fueron esas expectativas las que se vieron desafiadas. Y esta poesía reciente y cercana que se autodenominaba neobarroca no correspondía exactamente a lo que hubiera esperado, pero por momentos me provocaba sensaciones similares a las envolventes repeticiones o los contrastes dramáticos que quería seguir escuchando.

Me gustaría, ahora, tratar de restituir ese sorpresivo encuentro y profundizar un poco más en esas primeras intuiciones a partir de nuevas lecturas. Se trata de un esfuerzo algo extravagante, pues combinaré elementos de distintos siglos, continentes, soportes y tradiciones, que apenas comparten una vaga etiqueta. Pero confío en que podré rescatar algo de esta tensión para precisar qué comparten estas poéticas que me asombran, emocionan y confunden.

La vida de los flautistas dulces no es dulce. Nos empeñamos en tocar un instrumento que cualquiera puede hacer sonar. Es un instrumento escolar, casi de juguete. Su tesitura no es muy amplia, y sus posibilidades dinámicas son limitadas. Muchos piensan que es solo una etapa de transición, y constantemente nos preguntan cuándo comenzaremos a estudiar flauta traversa. Mi adorada esposa ha llegado a decir que la flauta dulce no es un instrumento: es un apostolado.

A pesar de todo, nos hemos esforzado históricamente por sacar el máximo provecho a estas limitaciones y competir con la expresividad de instrumentos más sofisticados como la viola da gamba o el cornetto, e incluso el canto. Ya en 1535, Silvestro Ganassi postulaba que la flauta dulce debía aspirar a imitar los distintos matices con que la voz humana expresa lo que quiere decir, variando la presión del aire y las digitaciones. Señalaba que incluso él había escuchado a algunos intérpretes en cuya música se podían percibir palabras (9). Esta búsqueda por la mayor expresividad posible se extendía, por supuesto, a todos los instrumentos, y se observa con frecuencia en las recomendaciones técnicas y estilísticas de los tratados musicales de los siglos siguientes. Más allá de las especificidades características de las distintas escuelas y sus respectivos desarrollos, existen algunos aspectos comunes destacables, como la flexibilidad rítmica en el fraseo. En 1676, Thomas Mace indicaba que, una vez que se ha aprendido a "mantener el tiempo" de manera consistente, podemos tomarnos la libertad para romperlo, acelerándolo o retrasándolo, para dar mayor gracia y brillo a la ejecución (Ohlsen 75). Este afán virtuoso se acentúa 
con la omnipresencia de los ornamentos de todo tipo (trinos, mordentes, apoyaturas, escalas, vibrato, flattement, etc.), que usualmente eran improvisados por el ejecutante. Carl Philipp Emanuel Bach, en 1735, declaraba su importancia sin titubeos: "No es cosa que alguien cuestione la necesidad de los ornamentos. Ellos están donde quiera que sea en la música y no sólo son útiles sino indispensables. Conectan los sonidos, les dan vida, los enfatizan y aparte de darles acento y significado los hacen graciosos. Ilustran los sentimientos, ya sean tristes o alegres. Ellos dan al ejecutante la posibilidad de mostrar su habilidad técnica y poder de expresión" (Ohlsen 87). Pero esta gama de recursos no debía utilizarse de manera caprichosa, sino en pos de una apelación lo más directa posible al auditor. Quien lo explicita de manera muy clara es Johann Joachim Quantz, en su método para aprender flauta traversa, de 1752: "La ejecución musical debe ser comparada con la entrega de un orador. Tanto el orador como el músico tienen, ambos, la misma intención con respecto a la preparación y la ejecución final de sus producciones. Ellos quieren tocar el corazón, excitar o apaciguar las emociones del alma y llevar al auditor de una pasión a otra" (Ohlsen 80).

Como bien señala Rubén López Cano, ya desde fines del siglo XVI hasta fines del XVIII, los teóricos musicales comenzaron a importar términos de la antigua retórica clásica en su intento por acentuar al máximo sus posibilidades persuasivas. Los compositores y teóricos lo reiteran una y otra vez: "Giulio Caccini (1601-2), por ejemplo, establece que el objetivo de la música es 'mover los afectos del alma'; Cesare Crivellati, en su Discorsi Musicali (1624), dedica todo un capítulo a 'cómo con la música se pueden mover diversos afectos'; Charles Butler (1636), por su parte, señala que la música, 'por sus varios modos', ejerce un 'gran poder sobre los afectos de la mente' y produce en el auditorio varios 'efectos"“ (López Cano 47), etc. En este período se explotan al máximo las capacidades de la música para despertar determinados estados emocionales, que entonces se denominaban "afectos" o "pasiones del alma". Tal como estudió Descartes en su influyente tratado Les Passions de l'Ame (1649), estas pasiones corresponden a un movimiento de los espíritus animales, que son las partes más ligeras de la sangre, y que cuando reciben un estímulo se dirigen hacia el cerebro y se manifiestan exteriormente en forma de sonrojo, suspiros, etc. Los compositores, mediante las distintas variables sonoras de las que disponían, buscaron precisamente la imitación de los movimientos corporales resultantes de la acción interna de un afecto (López Cano 58). Por ejemplo, el teórico Marin Mersenne (1636) propone reproducir los efectos de la cólera (mayor volumen de voz, aceleración del pulso, respiración apurada) mediante "un ritmo rápido y agitado en la melodía, precipitándose sobre todo al final de cada frase, a manera de alegoría de la agitación del pulso. Así mismo, el registro en que se canta se elevará, agudizándose, sobre todo, al final de cada frase en una segunda, cuarta, quinta o más, alegorizando el tono de voz con que se habla cuando se está encolerizado" (López Cano 59). Este proceso desemboca de manera correspondiente en los efectos hacia el auditor: "Cuando los elementos de una obra musical están construidos a imitación de los movimientos de cuerpo y espíritus generados por determinado afecto, ésta puede provocar en quien la escuche un movimiento de espíritus animales similar, y llevarlo a la misma pasión o afecto" (61). 
Un punto especial para los intérpretes es el principio de autoafectación, es decir, que se inunden "de la misma pasión que contiene la música", porque "sólo de este modo será capaz de despertar el mismo efecto en el auditorio" (68). Un anónimo espectador de Claudio Monteverdi en Venecia lo destaca elocuentemente: "alabado Monteverdi, que nació para dominar los afectos ajenos, pues no existe un ánimo tan duro que él no cambie y conmueva con su talento, adaptando de tal modo las notas musicales a las palabras y pasiones, que quien canta debe reír, llorar, encolerizarse, compadecerse y hacer todo aquello que éstas ordenan, siendo el oyente arrastrado de un ímpetu semejante a causa de la variedad y fuerza de las mismas perturbaciones" (López Cano 87). Quizás ese relato corresponda a la audición de alguno de los "Madrigali guerrieri ed amorosi", su radical libro VIII publicado en 1638. Allí Monteverdi relata una de sus propias búsquedas por representar los afectos, cuando descubre que mediante la repetición rapidísima de una misma nota puede expresar la ira y la vejación, el "stile concitato" que se escucha en una de sus obras más conocidas "Il Combattimento di Tancredi e Clorinda", compuesta sobre La Gerusalemme Liberata de Torquato Tasso.

Otro de los poetas que este compositor también musicalizó y que le inspiró la sugerente unión de erotismo y belicismo en esa misma colección fue Giambattista Marino, quien representa perfectamente a aquellos poetas obsesionados por romper las reglas y causar asombro (Buck 70). De acuerdo con August Buck, en esta época se fue configurando en la literatura una "estética del efecto", en la que los medios estilísticos también estaban subordinados al fin último del movere, es decir, causar "una impresión especialmente fuerte sobre el oyente o lector" (71). Un ejemplo contundente es el famoso poema de Marino dedicado a los besos. Cito a continuación un fragmento en el que no hay espacio para la contención, pues se busca impactar mediante una espectacular y virtuosa exacerbación de los sentidos:

Una bocca omicida, dolce d'Amor guerrera, cui natura di gemme arma ed inostra, dolcemente mi sfida, e schiva e lusinghiera, ed amante e nemica a me si mostra.

Entran scherzando in giostra

le lingue innamorate;

baci le trombe son, baci l'offesse,

baci son le contese;

quelle labra, ch'io stringo.

son l'agone e l'arringo;

vezzi son l'onte, e son le piaghe amate,

quanto profonde più, tanto più grate ${ }^{2}$ (Marino 303).

2 "Una boca homicida,/ dulce de Amor, guerrera,/ a la que la natura de perlas y de púrpura ha armado/ me provoca dulcemente,/ y esquiva y lisonjera,/ y enemiga y amante, 
III

Instrumentos que querían hablar, fraseos oscilantes, ornamentos por doquier, efectos, sorpresa, suspiros, sonrojos: ése era mi "barroco" de flautista dulce. Sus límites eran los de la retórica o microrretórica que he descrito; no era un barroco grande y consistente, sino muy parcial y pequeño. Aún no lo había situado en las perspectivas históricas o filosóficas, ni conocía sus implicancias a nivel eclesiástico e institucional, o sus mixturas culturales. Todavía no era el de Góngora, Sor Juana, Carpentier, Lezama Lima o Sarduy.

Pienso ahora en mi primera lectura de Medusario, la muestra compilada por Roberto Echavarren, José Kozer y Jacobo Sefamí, y trato de recordar algunos de sus primeros destellos. Mi vista y mi oído, como he dicho, estaban predispuestos, y por ello sentí una imantación mayor hacia aquellos autores en los que se evidenciaba con nitidez una sintaxis abigarrada, de ricas texturas, que se desplegaba en un movimiento continuo, y que recurría a la repetición de partículas sonoras como la base de sus variaciones. Cito algunos ejemplos que ya entonces me entusiasmaron, como el inicio de "La impregnación" de Reynaldo Jiménez, donde las palabras se aglutinan y confunden a partir de sus sonidos:

Donde dijera, afilado, cabellos, debiera resonar

caballos; donde imprecación, quizá imbricación, aun quizá invitación. desde la mano hasta la mano, se reparte el cosmos (Echavarren et al. 405).

O también "Lampos, lamedurías", de Eduardo Espina, en que la frase se extiende larguísimamente sin puntuación, siempre en metamorfosis:

Cuando bien dormido el deseo como

zorra zaherida en fábula de fiemo

donde a la alta lucidez huye en

la yesca allanando mi madriguera

ni della la sílaba venidera en un

haz de enamoramiento sino en pos

más bien del viento en la pradera

del disfrute de llenuras donde la

endeja de baba adamada de hada

en pijamas al pujar la pija en llamas (Echavarren et al. 436).

se me ofrece a la vista./ Como en un juego entran en competición/ las lenguas enamoradas;/ besos las trompas son y besos las ofensas, / besos son las disputas;/ esos labios que yo aprieto/ son combate y son liza;/ encantos son lujurias y las quejas amadas, y cuanto más profundas tanto más gratas son" (Colinas 231). 
O la envolvente rotación de "39 estrofas de comentario a una danza del autor . . ." de Mirko Lauer:

Sale de la ola, de una felicidad brevísima que no se encadena con otra felicidad; sale de la fantasmal transparencia del polietileno que entrega el tumbo adelgazado a contraluz. La luz aplasta el efímero telón con suculenta, violenta sacudida. Cuando sale del salón y de la sala, veo verde la ola con su colibrí, y lo veo verde, con su batahola. El mar es lo perecedero; el colibrí es su ingrávida dádiva (Echavarren et al. 137).

A pesar de estas primeras cercanías, también noté diferencias con mis costumbres de auditor de música barroca. Por una parte, el flujo discursivo de estos poemas muchas veces parecía azaroso, caótico o, para utilizar un término que en este contexto sí tiene bastante sentido, rizomático. Las fugas de la poesía de Coral Bracho, por ejemplo, no se resuelven ni reúnen como las de un elaborado contrapunto de los siglos XVII y XVIII. Asimismo, las frases intercaladas entre paréntesis por José Kozer, no son ornamentos que refuercen el sentido del conjunto, sino más bien lo dispersan, al contrario de lo que proponía Quantz, para quien los adornos "nunca deben contradecir los sentimientos predominantes en la melodía principal" (Ohlsen 82). Por otra parte, Jean Rousseau, en su Traité de la viole de 1687 , fomentaba las libertades solo en la medida en que "den placer, porque dar placer significa tener genio y bueno gusto" (Ohlsen 76), y esta expectativa se quiebra de modo evidente en muchos de los poetas de Medusario, quienes nos ofrecen una provocativa mezcla de registros dispares (delicado y lujoso, a veces, kitsch, y repugnante, en otras ocasiones), como se observa, entre otros, en Osvaldo Lamborghini.

De esta primera experiencia de lectura emergió, sin embargo, la intuición de que habían coincidencias entre esa música que escuchaba e intentaba tocar, y estos poemas. Para profundizar en este encuentro, había que situar el foco no tanto en sus dispares condiciones de origen, sino en sus efectos. Ésta es precisamente la acertada proposición de Roberto Echavarren en el prólogo de Medusario para establecer la conexión con sus antecedentes líricos:

La poesía barroca y la neobarroca no comparten necesariamente los mismos procedimientos, aunque ciertos rasgos pueden ser considerados, por sus efectos, equivalentes. Lo que comparten es una tendencia al concepto singular, no general, la admisión de la duda y de una necesidad de ir más allá de las adecuaciones preconcebidas entre el lenguaje del poema y las expectativas supuestas del lector, el despliegue de las experiencias más allá de cualquier límite (Echavarren et al. 17).

Y, en un ensayo sobre Perlongher, vuelve a afirmarlo: "Tanto el poema barroco, como el neobarroco, buscan un efecto sublime. Una intensidad, un salir de sí" (Perlongher, Poemas completos 266). Si para algo sirviera invocar una vez más la palabra barroco o neobarroco, me gustaría que fuera simplemente para evocar esa experiencia de intensidad. "Lo que nosotros queremos es intensidad", declaró Perlongher en una entrevista con el insoportable Enrique Symns (Papeles insumisos 300), y se había referido en términos similares al proceso de escritura de Alambres: "no contentarse con describir lo que 
'pasaba', sino pescar la intensidad", hasta "dejarse arrastrar por lo que llega, por lo que nos sacude o nos tremola" (Prosa plebeya 140). Esa intensidad es buscada por un ritmo "intuitivo" (Papeles insumisos 366), que en poemas como "Cadáveres" o "Canción de la muerte en bicicleta" actúa como los ostinatos o las variaciones en torno a una secuencia de compases en tantas obras del siglo XVII. Pero aún más relevante es cómo se refiere al modo de provocar una "inmanencia" (369) a partir de los efectos: "El barroco no va a hablar de amor, va a hacer el amor en el poema mismo. Por ejemplo, el amor atraviesa ciertas sonoridades hechas de susurros, gemidos, voces, una expresión casi corporal" (342). Así suena, por ejemplo, en "Opus jopo", uno de sus poemas incluidos en Medusario, donde la fluida enumeración se contornea para asombrar al lector: "Jadean los haras sus aros de peltre, jaleo lúcido, luminiscente en el rebote de las ligas en la película infusa, taza de té en los bordes del revoque. La trama, en ese punto, en la lisura de ese cascabel, serpeante, de esa rima de jade en los jabones de los pies, melecas, masca en el erizar de los penachos la promesa de un guantes" (Echavarren et al. 378). En estos versos, al igual que en muchos de Medusario, late la poética que también atrajo a tantos músicos y poetas del siglo XVII y XVIII, quienes supieron asediar los sentidos corporales de todas las maneras posibles para despertar las pasiones humanas.

\section{BIBLIOGRAFÍA}

Buck, August. Literatura Universal. Renacimiento y Barroco. Trad. Rafael de la Vega. Madrid: Gredos, 1982.

Colinas, Antonio, ed. Antología esencial de la poesía italiana. Madrid: Espasa Calpe, 1999.

Echavarren, Roberto et al. Medusario. Muestra de poesía latinoamericana. México: Fondo de Cultura Económica, 1996.

Ganassi, Silvestro. Opera Intitulata Fontegara [1535]. Ed. Hildemarie Peter. Trad. Dorothy Swainson. Nachdruck: Robert Lienau Musikverlag, 1997.

López Cano, Rubén. Música y retórica en el barroco. Barcelona: Amalgama Ediciones, 2011. Marino, Giambattista. Opere. Ed. Alberto Asor Rosa. Milán: Rizzoli Editore, 1967.

Monteverdi, Claudio. Madrigali guerrieri ed amorosi. Intr. Concerto Vocale. Dir. René Jacobs. Mas de Vert: Harmonia Mundi, 2002. CD.

Ohlsen, Óscar. La música barroca. Un nuevo enfoque. Santiago: Ediciones Universidad Católica de Chile, 1993.

Perlongher, Néstor. Poemas completos. Ed. Roberto Echavarren. Buenos Aires: La Flauta Mágica, 2012.

Papeles insumisos. Ed. Adrián Cangi y Reynaldo Jiménez. Buenos Aires: Santiago Arcos Editor, 2004.

Prosa plebeya. Ensayos 1980-1992. Ed. Christian Ferrer y Osvaldo Baigorria. Buenos Aires: Colihue, 1997. 